\title{
Evaluation of Bevacizumab for the Treatment of Epidural Fibrosis by Immunohistochemical Staining for CD105 and Osteopontin
}

\author{
Ilhan YILMAZ1', Uzay ERDOGAN², Osman TANRIVERDI², Omur GUNALDI², Utku ADILAY³, \\ Muhammed OMEROGLU ${ }^{4}$, Canan TANIK ${ }^{5}$, Bekir TUGCU² \\ 1University of Health Sciences, sisli Hamidiye Etfal Training and Research Hospital, Department of Neurosurgery, Istanbul, Turkey \\ ${ }^{2}$ University of Health Sciences, Bakirkoy Prof. Dr. Mazhar Osman Training and Research Hospital for Neurology, Neurosurgery and Psychiatry, \\ Department of Neurosurgery, Istanbul, Turkey \\ ${ }^{3}$ Balikesir University, Medical Faculty, Department of Neurosurgery, Balıkesir, Turkey \\ ${ }^{4}$ Toyotasa State Hospital, Neurosurgery Clinic, Sakarya, Turkey \\ ${ }^{5}$ University of Health Sciences, Sisli Hamidiye Etfal Training and Research Hospital, Department of Pathology, Istanbul, Turkey
}

\section{ABSTRACT}

AIM: To evaluate bevacizumab for epidural fibrosis (EF) treatment in an experimental rat model using histopathology as well as immunohistochemical staining for CD105 and osteopontin (OPN).

MATERIAL and METHODS: Sixteen Wistar Albino rats underwent either laminectomy alone to induce EF (group I, control) or laminectomy plus local bevacizumab treatment (group II). The degree of EF was compared between groups using the current histopathological grading method as well as immunohistochemistry for CD105 and OPN. In addition, the consistency of EF staging using CD105 and OPN expression was compared to that using histopathology.

RESULTS: The grade of EF was significantly lower in group II than in group I based on the fibroblast count and fibrosis density determined using histopathology, as well as by CD105 expression determined using immunohistochemistry. In contrast, OPN expression was not a reliable marker for EF evaluation because it did not show a significant difference between the two groups.

CONCLUSION: Bevacizumab prevents EF development as assessed using both histopathology and CD105 expression. CD105 is a potentially reliable marker for the immunohistochemical grading of EF, in contrast to OPN.

KEYWORDS: Bevacizumab, CD105, Epidural fibrosis, Osteopontin, VEGF

\section{INTRODUCTION}

$\mathrm{L}$ aminectomy is one of the most widespread surgical procedures in neurosurgery $(3,16)$. Although the development of epidural fibrosis (EF) after laminectomy is a natural process, advanced EF is associated with root pressure and tension as one of the most common causes of failed back surgery (6). As treatment approaches for EF are associated with high rates of complications and failed surgery, the main goal is the prevention of EF (11). Among many ongoing studies and research on EF prevention after laminectomy, anti-neoplastic agents are a special focus of interest (2).

The primary cause of EF is chemotactic factors released from lysed erythrocytes and thrombocytes in the surgical area after laminectomy and migration of fibroblasts originating from paraspinal muscles. Adhesions develop secondary to 
hyperplasia of fibrous connective tissue. Fibroblasts, which are major players in tissue repair, are activated by inflammatory cytokines and growth factors (transforming growth factor $\beta$ and basic fibroblast growth factor) and attempt to repair local defects in the vertebral laminae (Figure 1A). With the production of collagen fibrils, fibroblasts become fibrocytes; thus, scar tissue is formed from fibrous connective tissue (9).

Bevacizumab is a recombinant humanized monoclonal antibody raised against vascular endothelial growth factor (VEGF) that is used as an anti-neoplastic drug because of its anti-angiogenic function (23). By blocking VEGF receptors in damaged tissue, bevacizumab renders VEGF inactive, thereby preventing the formation of fibrous tissue through a reduction in angioneogenesis (Figure 1B) $(15,20,26)$. There is a recognized proportional relationship between the degree of angiogenesis and fibrotic tissue (24).

CD105 is a membrane glycoprotein that regulates signaling of transforming growth factor- $\beta 1$ (24). Several studies showed that CD105 was expressed by macrophages, erythroid precursors, syncytiotrophoblasts of terminal placenta, and stromal cells $(8,10,18,25)$. Importantly, although CD105 expression levels can be used to determine microvessel density in tumorassociated angiogenesis, there are no studies on its potential use in the determination of EF after laminectomy.

Osteopontin (OPN) is a small integrin-binding ligand, $\mathrm{N}$-linked glycoprotein that was first identified in cortical bone (21). OPN is synthesized by numerous cells containing fibroblasts $(1,13)$. Recent studies have shown that OPN plays a significant role in EF formation in rat peridural scar models (5). As it is expressed from inflammatory cells and fibroblasts, OPN can also be used in the determination of fibrosis (22).

Only one study has reported bevacizumab associated with EF development after spinal surgery (16). Therefore, we examined the mechanism underlying bevacizumab-mediated EF prevention using immunohistochemistry. Additionally, we assessed whether CD105, a marker of angiogenesis expressed by macrophages, and OPN, a marker of fibrosis, could be used as potential markers reflecting the degree of EF after laminectomy by immunohistochemistry and compared their utility to standard methods.

\section{MATERIAL and METHODS}

This study was approved by the experimental animal research ethics committee of Marmara University (04.01.2016/001) and conducted at the experimental animal laboratory of Marmara University. A total of 16 Wistar Albino rats with an average weight of $250 \pm 30 \mathrm{~g}$ were used. Throughout the experiment, all animals were housed in individual cages and received no medical treatment after the first procedure. Surgical intervention was achieved using microsurgical instruments.

\section{Surgical Procedure}

Sixteen Wistar Albino rats, aged 10-12 weeks, were used. Thirty minutes before surgery, a single dose of $50 \mathrm{mg} / \mathrm{kg}$ ceftriaxone (Rocephine, Roche, Turkey) was administered intraperitoneally as prophylaxis. General anesthesia was induced by intraperitoneal administration of $100 \mathrm{mg} / \mathrm{kg}$ ketamine hydrochloride $(50 \mathrm{mg} / \mathrm{ml}$; Ketalar, Parke-Davis,

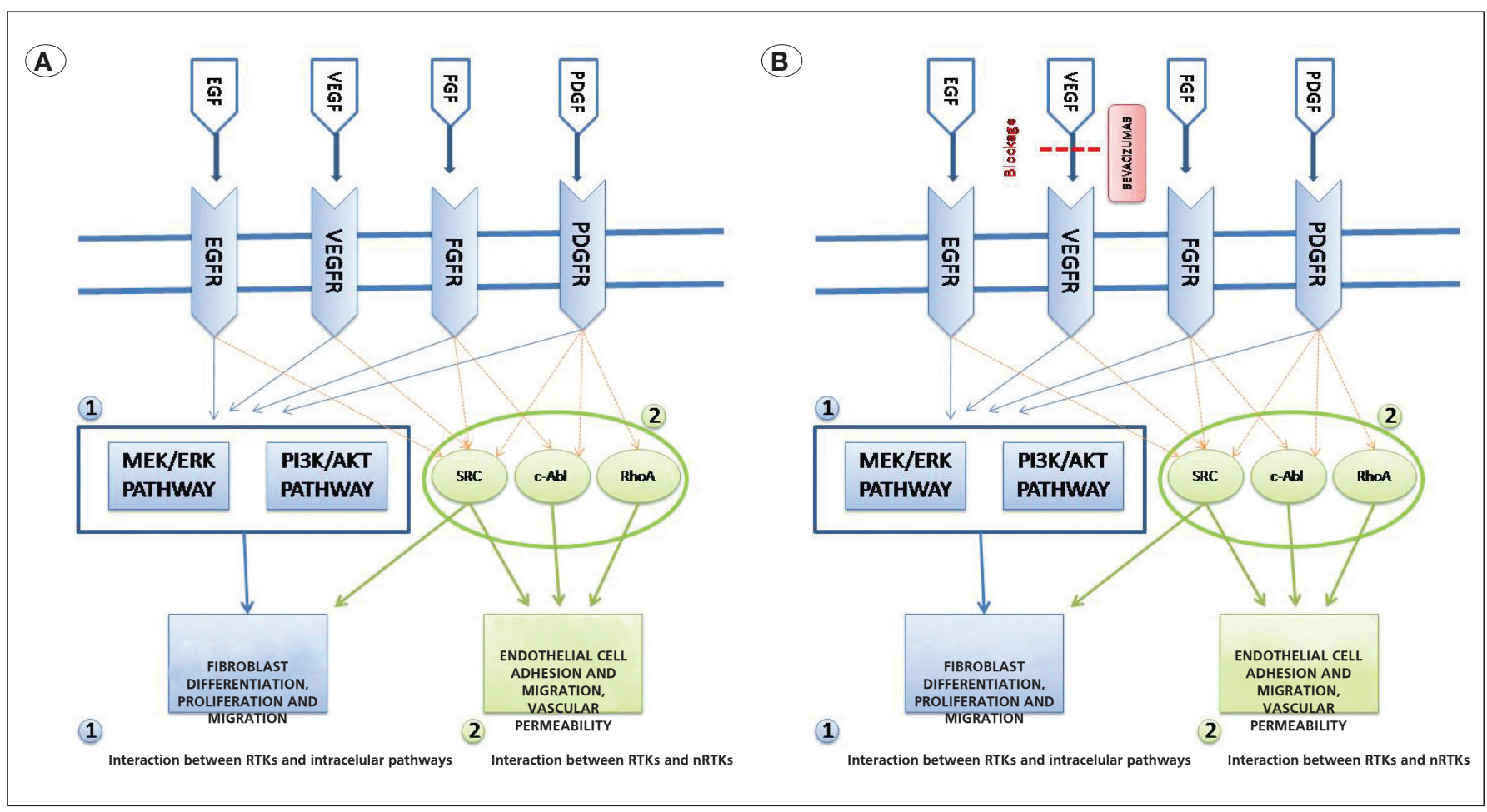

Figure 1A, B: Stages of epidural fibrosis development and proposed mechanism of fibrosis prevention by bevacizumab. 
Eczacibasi, Istanbul) and $10 \mathrm{mg} / \mathrm{kg}$ xylazine hydrochloride (Rompun 2\%, Bayer, Germany). Next, the rats were positioned at the operating table; the surgical site was disinfected with povidone iodine solution (Poviod; 10\% polyvinyl pyrrolidoneiodine complex, Saba, Turkey).

The surgical site was covered with sterile drapes. The L1-2 level of the spinal cord was identified, and a midline skin incision of approximately $2-2.5 \mathrm{~cm}$ was made at the L1-2 level. Paraspinous muscles were stripped with blunt dissection, total laminectomy was performed under surgical microscope to include an area of approximately $4 \mathrm{~mm}^{2}$ at the level of L1-L2, and the dural sac was exposed. Hemostasis during surgery was provided with saline irrigation. Bipolar cauterization, bone wax, or other hemostatic materials were not used.

Animals were divided into two groups. The control group (group I, n=8) underwent only laminectomy at the level of L1-2, and saline was applied to the surgical area. The treatment group (group II, $\mathrm{n}=8$ ) underwent L1-2 laminectomy and received topical bevacizumab (Avastin; Genentech, San Francisco, CA, USA) by the application of cotton wool soaked in bevacizumab to the laminectomy site for 5 minutes.

The incision area was sutured using 3/0 silk sutures, and all animals were sacrificed by cervical dislocation six weeks later. Evaluation before sacrifice determined that motor functions were normal in all animals and that there were no wound-site infections or other systemic pathologies. Relevant vertebral columns were removed en-bloc, together with the paraspinal muscles. Tissues were fixed in 10\% formalin (4\% formaldehyde), and pathological assessment was performed in a blinded manner. The amount of fibrosis in the laminectomy area and its relationship with the dura mater was compared within and between the experimental groups using previously published histological and immunohistochemical criteria, as detailed below.

\section{Histopathological Evaluation}

After 24 hours fixation in 10\% formalin buffer, the vertebral columns were decalcified with incubation in 10\% formic acid for two days. Following the decalcification process, specimens from each laminectomy site were collected, and the specimens were washed under running water for 6 hours, then the routine tissue follow-up procedure was applied in Leica $300 S$ Autotechnicon. The specimens were embedded into the paraffin wax and longitudinal sections of $3 \mathrm{~mm}$ thickness were prepared using a microtome and stained with Hematoxylin and Eosin (H\&E).

Specimens were examined at $40 \times$ magnification under light microscopy by an experienced pathologist who determined the extent of fibrosis and cell density arachnoid fibrosis. The extent of fibrosis in the dura mater was evaluated based on the criteria established by $\mathrm{He}$ et al. (Table I) $(11,12)$. The number of fibroblasts and inflammatory cells were determined based on the mean of a total of three areas in each specimen, including one area in the center and two areas at the edges of the laminectomy. The grading system for fibroblast and inflammatory cell counts was as follows: grade I, <100 fibroblasts/inflammatory cells per $400 \times$ field; grade II, 100-
150 fibroblasts/inflammatory cells per 400x field; grade III: >150 fibroblasts/inflammatory cells per 400x field (Table II). To increase accuracy, specimens were also stained with a monoclonal antibody against vimentin 1:100 (Vimentin clone: V9, LEICA Biosystems Nevcastle Upun Tyne-UK) to determine vimentin intensity as an indirect measurement of fibroblast numbers (30). Similarly, inflammatory cell density was assessed at 40x magnification. Furthermore, we evaluated the sections for bone renewal, winding of the nerve root and adhesions between dura and arachnoid layers (Figures 2A, B).

Bone regeneration, scar tissue encircling the nerve root, and adhesions in the dura-arachnoid gap were also recorded.

\section{Immunohistochemical Assessment}

Microvessel density in specimens was determined by immunohistochemical staining using monoclonal antibodies against OPN and CD105 and the streptavidin-biotin peroxidase method. The immunohistochemical study was done in the Leica Bond III. The slides are kept at $80^{\circ} \mathrm{C}$ in the incubator for 3 hours and installed in the Bond III device. From the primary antibodies, 1/400 dilution was prepared for CD105 (Clone EP274, catalog number AC-0243A, Epitomics, Burlingame, CA, USA) and 1/100 dilution was prepared for OPN (Clone EP106, catalog number AC-0102RUO; Epitomics, Burlingame, CA, USA). After automatized coloring, the slides are kept in xylene for 3 minutes and sealed.

\section{Assessment of Microvessel Density}

An Olympus CX41 light microscope was used to scan the slides stained with anti-CD105 and anti-OPN antibodies, and three different areas in each slide were selected as hot spots of neovascularization at low magnifications (40x and 100x). At 400x magnification, in each hot spot, brown-stained single endothelial cells that were separated from other connective tissue elements or clusters of endothelial cells were defined as a microvessel independently of the presence of a lumen

Table I: Criteria for Histopathological Grading of Scar Tissue by He et al. (12)

\begin{tabular}{cl}
\hline Grade & Extent of scar tissue \\
\hline $\mathbf{0}$ & No scar tissue in the dura mater \\
\hline $\mathbf{1}$ & $\begin{array}{l}\text { Fine fibrous bands present between the scar tis- } \\
\text { sue and the dura mater }\end{array}$ \\
\hline $\mathbf{2}$ & Adhesions on $<2 / 3$ of the laminectomy defect \\
\hline 3 & $\begin{array}{l}\text { Widespread scar tissue affecting }>2 / 3 \text { of the } \\
\text { laminectomy defect }\end{array}$ \\
\hline
\end{tabular}

Table II: Criteria for Histopathological Grading of Fibroblast Count

\begin{tabular}{cc}
\hline Grade & Mean fibroblast count (40x) \\
\hline $\mathbf{1}$ & $<100$ \\
\hline 2 & $100-150$ \\
\hline 3 & $>150$ \\
\hline
\end{tabular}



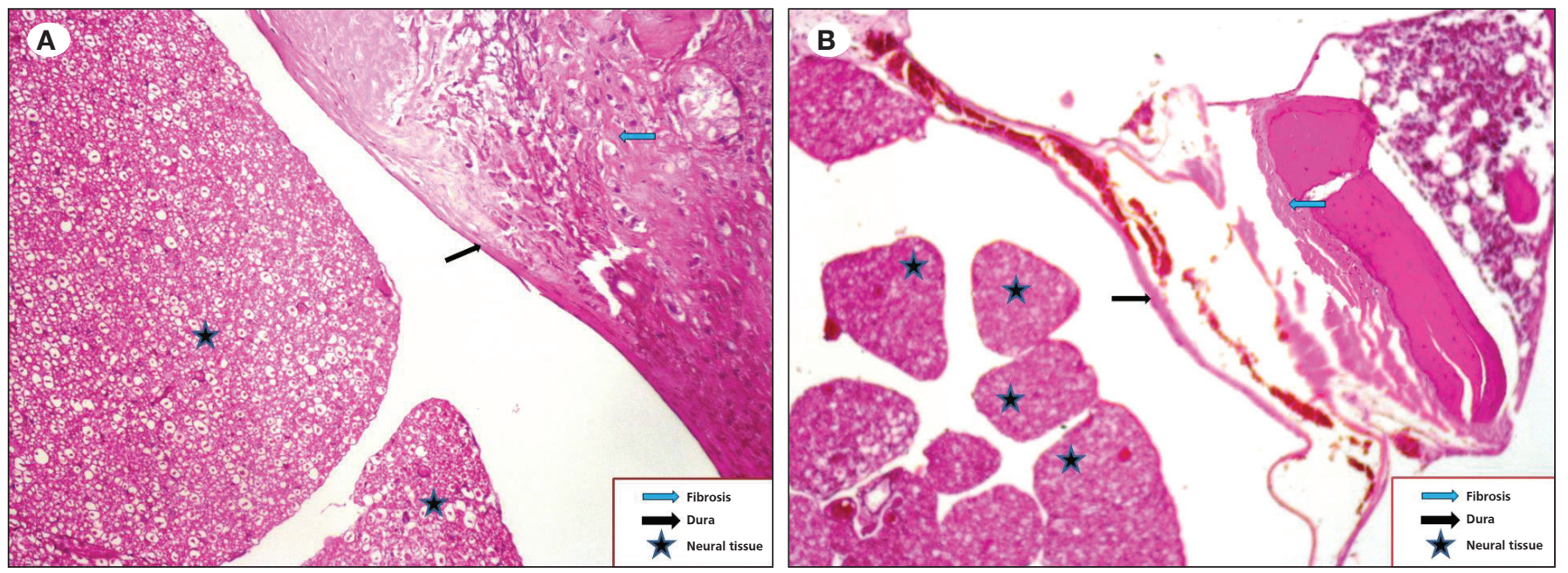

Figure 2: Histopathological examination of tissue slides using H\&E. A) Grade III fibrosis in a control animal in group I. B) Grade I fibrosis in a bevacizumab-treated animal in group II (star, neural tissue; black arrow, dura; blue arrow, fibrosis).

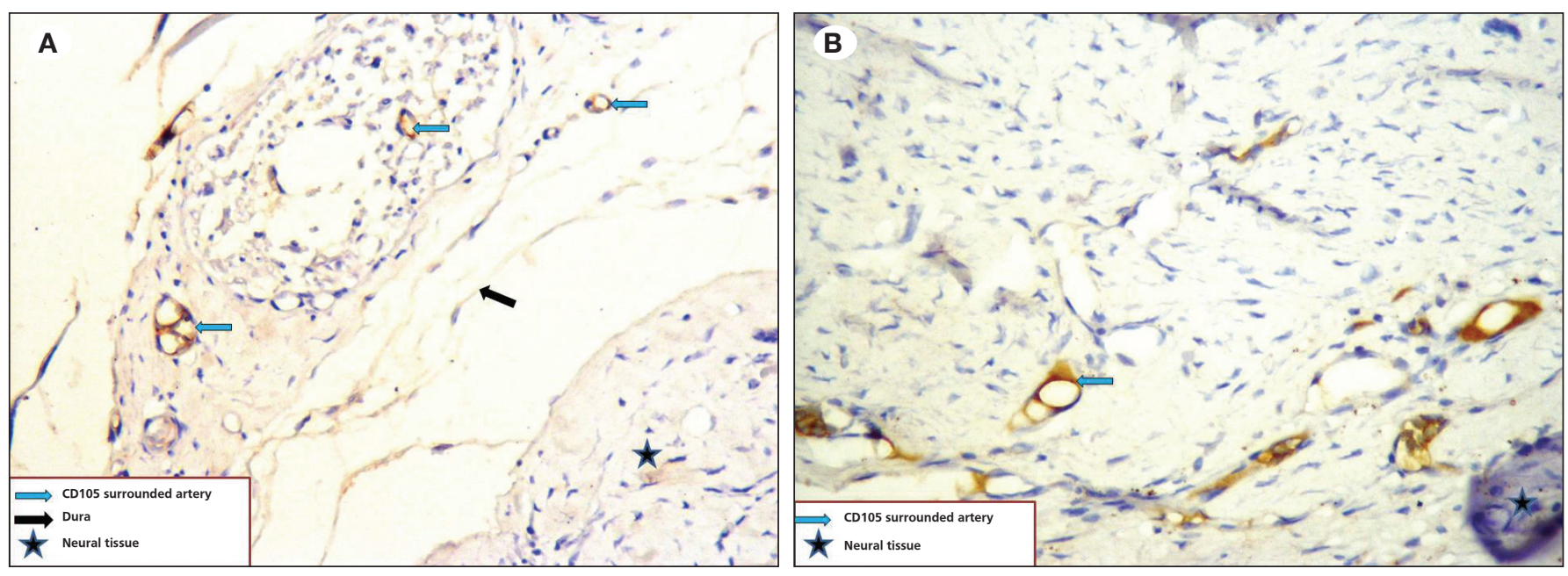

Figure 3: Immunohistochemical staining for CD105. A) Grade III fibrosis in a control animal in group I. B) Grade I fibrosis in a bevacizumabtreated animal in group II (star, neural tissue; black arrow, dura; blue arrow, fibrosis).
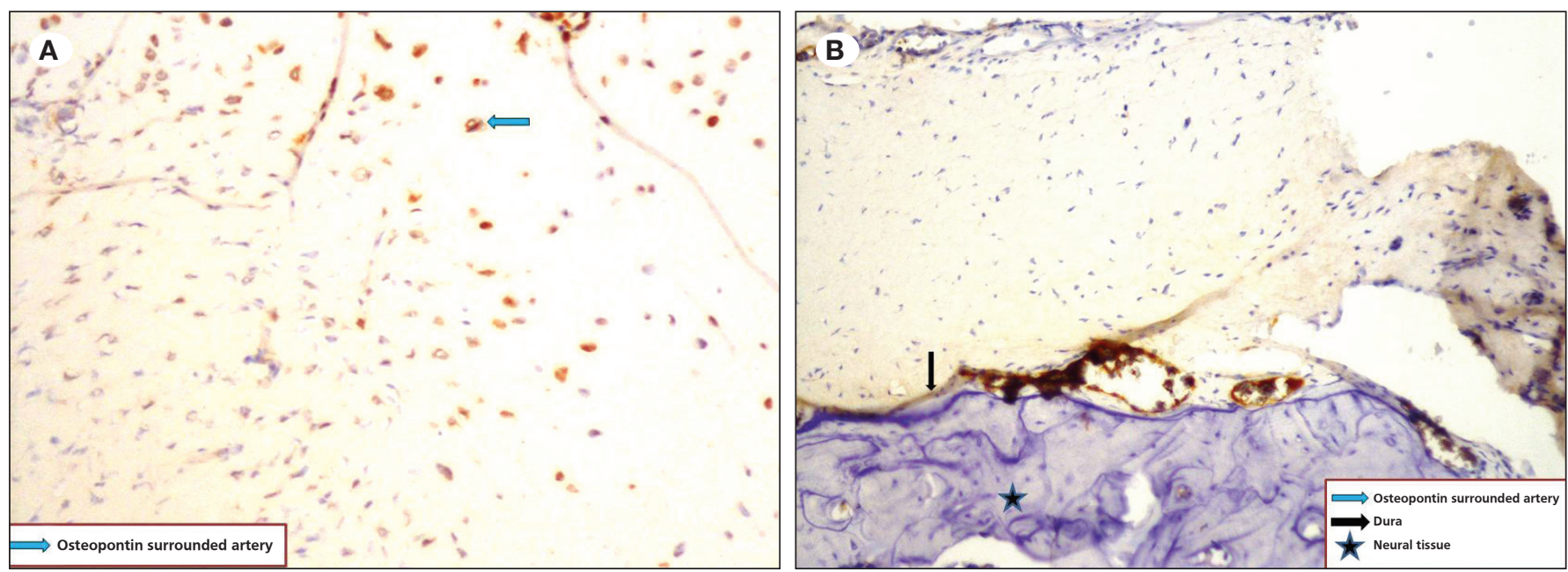

Figure 4: Immunohistochemical staining for osteopontin (OPN). A) Grade III fibrosis in a control animal in group I. B) Grade I fibrosis in a bevacizumab-treated animal in group II (star, neural tissue; black arrow, dura; blue arrow, fibrosis). 
(Figures 3A, B; 4A, B). Each slide was graded based on the number of vessels in each hot spot as follows: $\leq 3$, grade 1 ; $3-6$, grade 2; $\geq 7$, grade 3 (Table III). Vessels with a muscle layer were not accepted as newly formed vessels and were not included in the counting. The mean of the number of vessels in three hot spots for each slide was defined as the microvessel density in each animal.

\section{Statistical Analysis}

SPSS 15.0 for Windows (IBM, Armonk, NY, USA) was used for statistical analysis. Descriptive statistics are presented as numbers (n) and percentages (\%) for categorical variables. Categorical variables between the groups were tested using the chi-square test. When conditions were not met, a Monte Carlo simulation was applied. $p$ values $<0.05$ were considered as statistically significant.

\section{RESULTS}

There were significant differences in fibrosis grade $(p=0.001)$, density of fibroblasts $(p<0.001)$, density of inflammatory

Table III: Criteria for Grading Microvessel Count by Immunohistochemical Staining for CD105

\begin{tabular}{cc}
\hline Grade & Mean vessel count (400x) \\
\hline 1 & $\leq 3$ \\
\hline 2 & $4-6$ \\
\hline 3 & $\geq 7$ \\
\hline
\end{tabular}

cells $(p=0.001)$, and CD105 ratio $(p=0.001)$ between the bevacizumab and control groups (Table IV). Grade 0-1 fibrosis was higher in group II (bevacizumab treated animals), whereas grade 3 fibrosis was higher in group I (control animals). Furthermore, all cases in group II exhibited grade 1 fibroblast density, whereas all cases in group I exhibited grade 3 fibroblast density. Fibroblast density was graded the highest in $100 \%$ of Group 1 animals, but remained at grade 1 in Group II. Inflammatory cell density and CD105 grade 1 were high in group II and grade 3 was high in group I. No significant difference was found in OPN grades between the groups $(p=0.493$; Figure $5 A, B)$.

All animals (100\%) in group I had grade 3 fibrosis, whereas $3(37.5 \%)$ and $5(62.5 \%)$ animals were determined to exhibit grade 0 and 1 fibrosis, respectively, in group II. Therefore, the rate of EF based on the fibrosis grade was significantly lower in group II than in group I ( $p=0.001$; Table IV, Figure 5A, B).

All animals in group I had grade 3 fibroblast counts, whereas all animals in group II (100\%) exhibited grade 1 fibroblast counts. Therefore, the rate of EF was based on the fibroblast count was significantly lower in group II than in group I $(p<0.001$; Table IV, Figure 5A, B).

The extent of EF was also assessed based on the inflammatory cell density, which revealed that $2(25 \%)$ and $6(75 \%)$ animals in group I exhibited grades 3 and 2, respectively. Conversely, all animals (100\%) in group I exhibited grade 2 inflammatory cell density; therefore, the rate of EF according to this grading was also significantly lower in group II than in group I $(p=0.001$; Table IV, Figure 5A, B).

Table IV: Grading of Epidural Fibrosis Based on Fibrosis Score, Fibroblast and Inflammatory Cell Counts, and CD105 and OPN Expression By Immunohistochemistry

\begin{tabular}{|c|c|c|c|c|c|c|}
\hline & & \multicolumn{2}{|c|}{ Control } & \multicolumn{2}{|c|}{ Bevacizumab } & \multirow[b]{2}{*}{$\mathbf{p}$} \\
\hline & & $\mathbf{n}$ & $\%$ & $\mathbf{n}$ & $\%$ & \\
\hline \multirow[t]{3}{*}{ Fibrosis score } & Grade 0 & 0 & 0.0 & 3 & 37.5 & 0.001 \\
\hline & Grade 1 & 0 & 0.0 & 5 & 62.5 & \\
\hline & Grade 3 & 8 & 100 & 0 & 0.0 & \\
\hline \multirow[t]{2}{*}{ Fibroblast Count } & Grade 1 & 0 & 0.0 & 8 & 100 & $<0.001$ \\
\hline & Grade 3 & 8 & 100 & 0 & 0.0 & \\
\hline \multirow[t]{3}{*}{ Inflammatory Cell Count } & Grade 1 & 0 & 0.0 & 8 & 100 & 0.001 \\
\hline & Grade 2 & 2 & 25.0 & 0 & 0.0 & \\
\hline & Grade 3 & 6 & 75.0 & 0 & 0.0 & \\
\hline \multirow[t]{3}{*}{ CD105 } & Grade 1 & 0 & 0.0 & 8 & 100 & 0.001 \\
\hline & Grade 2 & 2 & 25.0 & 0 & 0.0 & \\
\hline & Grade 3 & 6 & 75.0 & 0 & 0 & \\
\hline \multirow[t]{3}{*}{ Osteopontin } & Grade 1 & 4 & 50.0 & 6 & 75.0 & 0.493 \\
\hline & Grade 2 & 2 & 25.0 & 2 & 25.0 & \\
\hline & Grade 3 & 2 & 25.0 & 0 & 0.0 & \\
\hline
\end{tabular}




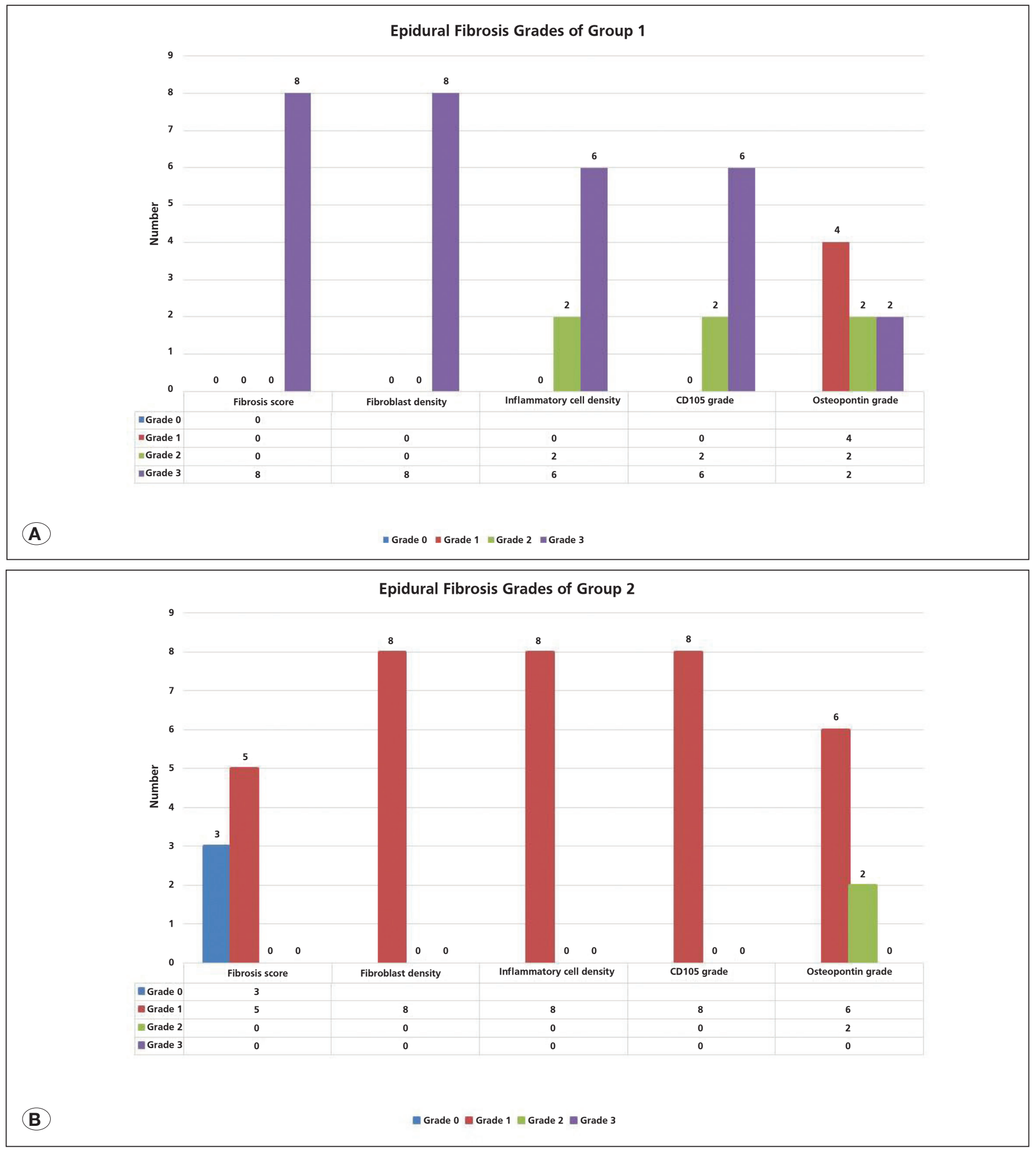

Figure 5: Distribution of epidural fibrosis in the control (group I) (A) and treatment (group II) (B) groups, according to the grading methods. 
Yilmaz I. et al: Bevacizumab for Epidural Fibrosis

The EF grading according to the CD105 staining revealed that $2(25 \%)$ and $6(75 \%)$ animals in group I were grades 2 and 3 , respectively, whereas all animals (100\%) in group II were grade 1. Accordingly, the rate of EF using this parameter was significantly lower in group II than in group I $(p=0.001$; Table IV, Figure 5A, B).

Finally, the EF grading according to the OPN staining demonstrated that $4(50 \%), 2(25 \%)$, and $2(25 \%)$ of the animals in group I had grade 1,2, and 3 OPN expression, respectively. Conversely, in group II, $6(75 \%)$ and $2(25 \%)$ animals were determined as grades 1 and 2, respectively, and there was no significant difference in OPN expression between the two groups, as a parameter to determine EF development $(p=0.493$; Table IV, Figures 5A, B).

\section{- DISCUSSION}

EF is one of the most common causes of failed back surgery following laminectomy, one of the widely used neurosurgical procedures. Treatment of EF is difficult and has a high complication rate, and associated costs are extremely high. Therefore, most of the previous studies were aimed at EF prevention rather than treatment (11). A better understanding of the factors that lead to the development of EF, as well as the underlying mechanisms, is necessary. The various factors associated with an increased rate of EF after laminectomy include the presence of a wide, dead cavity associated with a major surgery site, greater accumulation of blood products in an environment associated with insufficient bleeding control, infection, foreign body, excessive retraction, and use of bipolar cautery (2).

The role of angiogenesis in the development of EF is not known (7). VEGF is a strong angiogenic cytokine that also protects endothelial cells from radiation and stress-induced apoptosis. VEGF also directly contributes to tissue regeneration including remodeling, normal fibroblast functions, wound-healing and inflammatory response (14). Bevacizumab is a monoclonal VEGF antibody that is used primarily as an anti-cancer agent. By blocking VEGF receptors in damaged tissue, bevacizumab renders VEGF inactive and inhibits angiogenesis, $(15,20)$. Angiogenesis is also a critical step in wound healing, and the extent of fibrotic tissue correlates with the degree of angiogenesis. Previous studies demonstrated the effect of bevacizumab on fibrosis, and findings support a role for bevacizumab in reducing EF (16), which was shown to associate with its anti-angiogenic property (16). However, to the best of our knowledge, no studies investigated the mechanism underlying the prevention of EF by the anti-angiogenic effect of bevacizumab by using immunohistochemistry.

In the current study, the extent of EF, fibrosis score, the number of fibroblasts and inflammatory cells, and the expression levels of CD105 and OPN were evaluated, which revealed successful EF development in all animals in group I. In addition, the extent of EF was lower in animals that received local bevacizumab in group II than those in the control group I. Among the markers used to evaluate the degree of EF, fibrosis score, the number of fibroblasts and inflammatory cells, and CD105 expression reflected consistent results, whereas grading for EF using OPN expression was not consistent with the other methods used for evaluation of the EF in the current study. Importantly, no toxic effects of bevacizumab were observed in the dura mater, paraspinal muscles, or other tissues.

The extent of angiogenesis can be determined directly in tumor and/or fibrotic tissue by measurement of microvessel density. An increase in the number of microvessels indicates a strong angiogenic response (17). Staining for proteins expressed in the endothelial cell membrane using immunohistochemical methods is utilized to determine microvessels in fibrotic tissue. To date, no study has used CD105, a potential immunohistochemical marker for microvessel density, to examine the extent of EF after laminectomy using immunohistochemistry. Anti-CD105 binds to endothelial cells in angiogenic tissue, whereas it is either undetectable or weakly stains normal tissue. Therefore, staining for CD105 is an ideal approach for the evaluation of angiogenesis $(28,29)$. Furthermore, anti-CD105 is highly selective for blood vessel endothelium and reacts specifically with endothelial cells only, without evident staining in inflammatory or stromal cells (4). Therefore, determination of the extent of EF with anti-CD105 reduces the likelihood of false-positive blood vessel staining. In the current study, grading of EF based on microvessel density as assessed by CD105 immunostaining was consistent with the grading based on fibroblast count and fibrosis density. This result supports CD105 as potentially an objective and suitable immunohistochemical marker for EF determination, as an alternative to other currently used methods, which is a novel finding of the current study.

Another potential immunohistochemical marker for the evaluation of fibrosis is OPN, which participates in tissue remodeling, macrophage and neutrophil migration, angiogenesis, and the formation of collagen fibrils during wound healing (27). OPN also plays an important anti-inflammatory role in acute and chronic inflammation, preventing or reducing the severity of inflammation (19). The current study is the first to compare OPN as a potential immunohistochemical marker with current methods to determine the grade of EF after laminectomy. However, our findings did not show OPN as a consistent marker comparable with the established histopathological methods for EF or CD105 staining. Therefore, OPN expression using immunohistochemistry might not be a reliable marker in the determination of EF.

Only one study thus far investigated the effect of bevacizumab on spinal EF (16). It found that bevacizumab reduced the development of EF following experimental laminectomy, as assessed by histopathological evaluation. In contrast to that study, which did not utilize immunohistochemistry, the current study used both histopathology and immunohistochemistry to assess the effect of bevacizumab on EF development and demonstrated that EF was significantly reduced by local application of bevacizumab, which reduced neovascularization in damaged tissue, as determined by CD105 immunostaining; however, OPN was not a reliable marker. 


\section{CONCLUSION}

Local application of bevacizumab after laminectomy significantly reduces EF. Whereas CD105 is a reliable marker for EF evaluation, consistent with grading using established methods. Grading using OPN immunostaining is not reliable. No local toxic or systemic side effects were observed with bevacizumab, suggesting its potential utility in clinical studies.

\section{ACKNOWLEDGEMENT}

Preparation for publication of this article was partly supported by the Turkish Neurosurgical Society.

\section{REFERENCES}

1. Ashizawa N, Graf K, Do YS, Nunohiro T, Giachelli CM, Meehan WP, Tuan TL, Hsueh WA: Osteopontin is produced by rat cardiac fibroblasts and mediates A(II)-induced DNA synthesis and collagen gel contraction. J Clin Invest 98:2218-2227, 1996

2. Aydincak O, Yilmaz MB, Emmez H, Kurt G, Sepici A, Memis L, Baykaner K: The effect of temozolomide on the prevention of epidural fibrosis developing after lumbar laminectomy in rats. Turk Neurosurg 22:706-711, 2012

3. Barbera J, Gonzalez J, Esquerdo J, Broseta J, BarciaSalorio JL: Prophylaxis of the laminectomy membrane. An experimental study in dogs. J Neurosurg 49:419-424, 1978

4. Brewer CA, Setterdahl JJ, Li MJ, Johnston JM, Mann JL, McAsey ME: Endoglin expression as a measure of microvessels density in cervical cancer. Obstet Gynecol 96:224-228, 2000

5. Brzezicki G, Jankowski R, Blok T, Klimczak A, Szymas J, Huber J, Szukala A, Siemionow M, Nowak S: Postlaminectomy osteopontin expression and associated neurophysiological findings in rat peridural scar model. Spine 36:378-385, 2011

6. de Tribolet N, Robertson JT: Lack of post discectomy adhesions following application of Adcon-L: A case report. Eur Spine J 1:18-20, 1996

7. Fayette J, Soria JC, Armand JP: Use of angiogenesis inhibitors in tumour treatment. Eur J Cancer 41:1109-1116, 2005

8. García-Pozo L, Miquilena-Colina ME, Lozano-Rodríguez T, García-Monzón C: Endoglin: Structure, biological functions, and role in fibrogenesis. Rev Esp Enferm Dig 100: 355-360, 2008

9. Geisler $\mathrm{FH}$ : Prevention of peridural fibrosis: Current methodologies. Neurol Res 21:9-22, 1999

10. Gougos A, St Jacques S, Greaves A, O'Connell PJ, d'Apice $A J$, Bühring $H J$, Bühring $H J$, Bernabeu $C$, van Mourik JA, Letarte M: Identification of distinct epitopes of endoglin, an RGD-containing glycoprotein of endothelial cells, leukemic cells, and syncytiotrophoblasts. Intern Immunol 4:83-92, 1992

11. Gunaldi O, Erdogan S, Guclu DG, Tugcu B, Ofluoglu E, Baydin S, Emel E: "Honey" can prevent epidural fibrosis development after laminectomy: An experimental study. Turk Neurosurg 24:849-854, 2014

12. He Y, Revel M, Loty BA: A quantitative model of postlaminectomy scar formation: Effects of a nonsteroidal antiinflammatory drug. Spine 20: 557-563, 1995
13. Herring GM, Kent PW: Some studies on mucosubstances of bovine cortical bone. Biochem J 89:405-414, 1963

14. Howdieshell TR, Callaway D, Webb WL, Gaines MD, Procter CD Jr, Sathyanarayana, Pollock JS, Brock TL, McNeil PL: Antibody neutralization of vascular endothelial growth factor inhibits wound granulation tissue formation. J Surg Res 96: 173-182, 2001

15. Hsei V, Deguzman GG, Nixon A, Gaudreault J: Complexation of VEGF with bevacizumab decreases VEGF clearance in rats. Pharm Res 19: 1753-1756, 2002

16. Karatay M, Erdem Y, Koktekir E, Erkoc YS, Caydere M, Bayar MA: The effect of bevacizumab on spinal epidural fibrosis in a postlaminectomy rat model. Turk Neurosurg 22:753-757, 2012

17. Koukourakis MI, Giatromanolaki A, Thorpe PE, Brekken RA, Sivridis E, Kakolyris S, Georgoulias V, Gatter KC, Harris AL: Vascular endothelial growth factor/KDR activated microvessel density versus CD31 standard microvessel density in nonsmall cell lung cancer. Cancer Res 60: 3088-3095, 2000

18. Lastres P, Bellon T, Cabañas C, Sanchez-Madrid F, Acevedo A, Gougos A, Letarte M, Bernabeu C: Regulated expression on human macrophages of endoglin, an Arg-Gly-Asp-containing surface antigen. Eur J Immunol 22: 393-397, 1992

19. Mazzali M, Kipari T, Ophascharoensuk V, Wesson JA, Johnson $\mathrm{R}$, Hughes J: Osteopontin- a molecule for all seasons. QJM 95: 3-13, 2002

20. Mello GR, Pizzolatti ML, Wasilewski D, Santhiago MR, Budel $\mathrm{V}$, Moreira $\mathrm{H}$ : The effect of subconjunctival bevacizumab on corneal neovascularization, inflammation and re-epithelization in a rabbit model. Clinics 66:1443-1450, 2011

21. Oldberg A, Franzen A, Heinegard D: Cloning and sequence analysis of rat bone sialoprotein (osteopontin) cDNA reveals an Arg-Gly-Asp cell-binding sequence. Proc Natl Acad Sci USA 83: 8819-8823, 1986

22. Pereira P, Avelino A, Monteiro P, Vaz R, Castro-Lopes JM: New insights from immunohistochemistry for the characterization of epidural scar tissue. Pain Physician 17: 465-474, 2014

23. Presta LG, Chen H, O'Connor SJ, Chisholm V, Meng YG, Krummen L, Winkler M, Ferrara N: Humanization of an antiVEGF monoclonal antibody for the therapy of solid tumors and other disorders. Cancer Res 57:4593-4599, 1997

24. Prieto $M$, Rodriguez-Pena A, Arevalo M, Rivas JV, Duwel A, Eleno N, Sánchez RJ, Morales Al, López-Novoa JM, Pérez-Barriocanal F: Effect of the long term treatment with trandolapril on endoglin expression in rats with experimental renal fibrosis induced by renal mass reduction. Kidney Blood Press Res 28:32-40, 2005

25. St Jacques S, Cymerman U, Pece N, Letarte M: Molecular characterization and in situ localization of murine endoglin reveal that it is a transforming growth factor- $\beta$ binding protein of endothelial and stromal cells. Endocrinology 134:26452657, 1994

26. Tran J, Master Z, Yu JL, Rak J, Dumont DJ, Kerbel RS: A role for survivin in chemoresistance of endothelial cells mediated by VEGF. Proc Natl Acad Sci USA 99:4349-4354, 2002 
27. Vetrone SA, Montecino-Rodriguez E, Kudryashova E, Kramerova I, Hoffman EP, Liu SD, Miceli MC, Spencer MJ: Osteopontin promotes fibrosis in dystrophic mouse muscle by modulating immune cell subsets and intramuscular TGF-beta. J Clin Invest 119:1583-1594, 2009

28. Weidner N: The importance of tumor angiogenesis: The evidence continues to grow. Am J Clin Pathol 122:675-677, 2004
29. Yao Y, Kubota T: Prognostic significance of microvessel density determined by an anti-CD105/endoglin monoclonal antibody in astrocytic tumors: Comparison with an anti-CD31 monoclonal antibody. Neuropathology 25:201-206, 2005

30. Zhang C, Kong X, Zhou H, Liu C, Zhao X, Zhou X, Su Y, Sharma HS, Feng S: An experimental novel study; Angelica sinensis prevents epidural fibrosis in laminectomy rats via downregulation of hydroxyproline, IL-6, and TGF- $\beta$ 1. Evid Based Complement Alternat Med 2013: 291814, 2013 